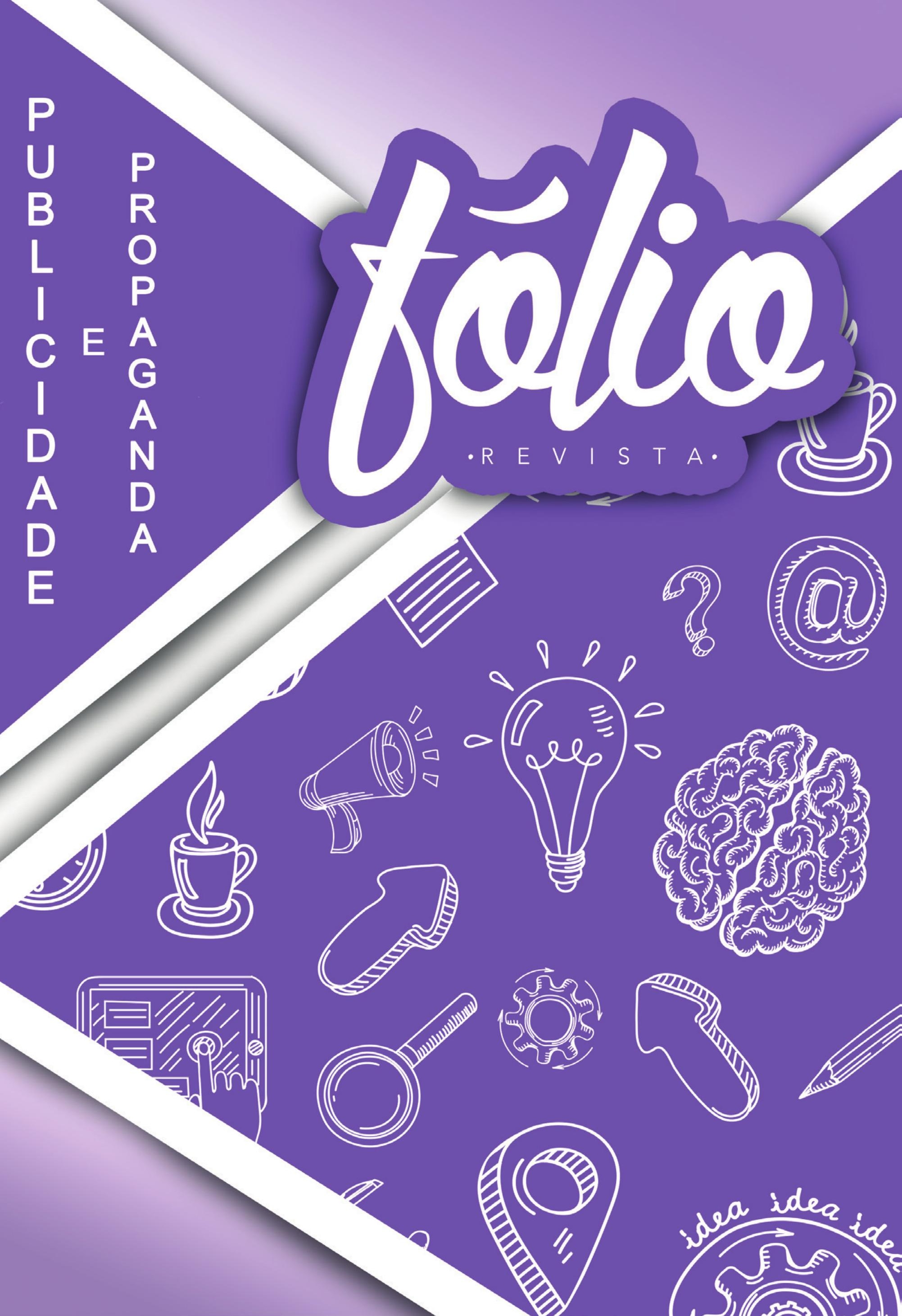




\section{A evolução da comunicação a partir dos dispositivos móveis e o seu impacto nas estratégias de marketing}

\section{The evolution of communication from mobile devices and its impact in marketing strategies}

\section{Suelen Backes ${ }^{1}$}

\section{Resumo}

O presente artigo trata sobre a evolução da comunicação a partir da Internet e do surgimento dos dispositivos móveis que interferem na cultura da sociedade e nas estratégias de marketing. No momento em que as pessoas carregam consigo um computador de bolso, como os smartphones e a partir deles conseguem interagir com o mundo, fazendo suas pesquisas, trabalhando, estudando, ou simplesmente postando/comentando/compartiIhando informações nas suas redes sociais, elas acabam tendo mais poder, pois sentem que podem participar e interferir nos campos sociais. Sabendo disso, instituições comerciais, através de softwares gratuitos como o $4 \mathrm{~K}$ Stogram, podem fazer análises das postagens de conteúdos dos indivíduos e trabalhar estratégias de comunicação e marketing com base nas informações que eles mesmos publicam.

Palavras-chave: Comunicação. Tecnologia. Dispositivos móveis. 4K Stogram. Marketing.

\section{Abstract}

The following article covers the evolution of communication over the internet and the emergences of mobile devices which interfere on our culture and on marketing strategies. From the moment where everyone carries a pocket computer, such as smartphones, and with them they can interact with the world, doing their researches, working, studying or simply posting/commenting/sharing information on their social networks, they end up having more power because of the real feeling of being able to participate and interfere in the social fields. Knowing this, commercial companies, by using software such as 4K Stogram which are free of charge, can make analyses of contents from the postings of individuals and work on communication strategies and marketing based on this data that people publish themselves.

Keywords: Communication. Technology. Mobile Devices. 4K Stogram. Marketing.

\footnotetext{
1 Mestranda em Comunicação Social, pela Pontifícia Universidade Católica do Rio Grande do Sul - PUC/RS. Bolsista CNPq. Jornalista. su_backes@yahoo.com.br.
} 


\section{Introdução}

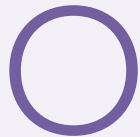
presente artigo busca refletir as mudanças ocorridas ao longo dos anos, de uma sociedade analógica para a digital e compreender os impactos desses fenômenos no dia a dia de trabalho das pessoas, nos estudos, no lazer, nos cuidados com a saúde, na locomoção, entre outros, uma vez que a conexão atual transpassa o ambiente físico. A partir da participação assídua de mais pessoas na Web, manifestando suas opiniões a respeito de comportamentos, lugares, produtos e serviços, os gestores conseguem captar, de forma gratuita, opiniões sinceras de pessoas que consomem seus produtos e serviços e uma boa fonte de informações para adequarem, cada vez mais, o que oferecem ao mercado, a partir do perfil do público que consome e das suas preferências.

Com o estímulo ao empreendedorismo, as pessoas estão sendo desafiadas a tirar as suas ideias do papel e abrir o seu próprio negócio, mesmo que não tenham todos os conhecimentos teóricos e práticos, nem os recursos financeiros e tecnológicos para tal desde o início. Porém, tendo interesse em compreender mais o seu público e sabendo que isso é fundamental para o sucesso do negócio, por meio da literatura e de softwares gratuitos, é possível fazer uma série de levantamento de comportamento do mercado e isso contribui para o crescimento e a reputação da marca.

Assim, o presente artigo é uma reflexão sobre a interferência da tecnologia na sociedade e a junção do humano com o digital, especialmente a necessidade, cada vez maior, por parte dos empresários, de transformar os comportamentos sociais em dados quantificáveis para serem aplicados aos seus negócios. Percebe-se que, cada vez mais, a participação espontânea do público nas redes sociais vêm transformando o jeito de pensar e de fazer comunicação a partir de dados gratuitos.

Para tanto, o presente texto conta com embasamento teórico de Anderson (2006), Cobra (1997), Jenkins (2014), Mattelart (1999), Negroponte (1995), Recuero (2014), Ugarte (2008) entre outros pesquisadores, e um exemplo prático aplicado a partir do software 4K Stogram², como uma possibilidade de pesquisa de oportunidade, de consumo e de satisfação, como ferramenta de apoio às estratégias de marketing.

\section{Comunicação, conexão e consumo}

O jeito de fazer, consumir e distribuir comunicação vem sendo constantemente modificado especialmente desde a década de 1990, com a popularização e o fácil acesso à Internet, que trouxe agilidade para a realização das atividades do dia a dia e mais ainda com o surgimento dos dispositivos móveis nos primeiros anos do século XXI. As novas tecnologias configuram uma nova forma de viver e se relacionar, representada pelas transformações de tempo e espaço, que constituem o que Martins (2000) denomina o "tempo de redes", um tempo não cronológico e midiático relacionado a um espaço não físico, virtual. Chega-se, assim, a uma nova formulação de sociedade: "uma sociedade que é definida em termos de comunicação, que é definida em termos de redes" (MATTELART, 1999, p.157).

Hoje, pela múltipla opção de interesses, pelo acesso à informação e ao crédito, as pessoas não podem mais ser rotuladas pelo seu poder aquisitivo ou pelo que consomem. Exemplos disso são as várias pessoas que moram na periferia, mas têm smartphone de última geração; aqueles que têm uma casa modesta, mas contam com um carro de alto padrão na garagem; ou ainda, pessoas que pela facilidade de poderem parcelar suas férias, viajam para diversos países do mundo, tanto quanto uma pessoa com condições de organizar seus roteiros em agências de turismo e pagando à vista têm. Sem contar a mudança de comportamento. Está muito mais difícil rotular uma pessoa pela graduação que ela optou cursar, com os gostos por comidas, ou lugares que frequenta e pelas preferências musicais, porque a sociedade está muito mais horizontal e, tendo consciência

2 Disponível em http://www.techtudo.com.br/tudo-sobre/4kstogram.html. Acesso em 02 de jul. 2017. 
de que estão vivendo por mais tempo, as pessoas têm se permitido fazer, experimentar e gostar de coisas bem distintas.

Ao longo da vida, as pessoas vão descobrindo outras aptidões, vontades e se permitindo desenvolvê-las e agregando conhecimentos múltiplos ao seu saber e ao seu currículo, conhecendo pessoas de áreas de atuação distintas e outras ocupações que vão despertando interesse. Essa é a base da sociedade em rede, que, de acordo com Ugarte (2008): "os indivíduos vivem e representam vidas não separadas, vidas em que o político, o profissional e o pessoal estão categorizados em compartimentos" (p.52).

Antes das redes sociais, falava-se em uma espécie de vida particular/privada e de uma vida social/profissional/pública. Hoje, com a oportunidade de cada indivíduo ter o seu espaço de expressão na web, mostram para o mundo quem são, quem são os seus amigos, com quem estão, onde estão, suas preferências e estilos, crenças e opiniões variadas acerca de valores, atitudes e de comportamentos. Vivem um estilo de vida baseado no fortalecimento coletivo e individual das pessoas frente ao poder.

A essência da sociedade atual é a conexão e a interação entre as pessoas. Uma pessoa sozinha dificilmente muda uma cultura ou opinião já formada, mas se estiver relacionada a várias outras, o discurso ganha força e apoiam ou desaprovam atitudes e legitimam ou contestam variadas relações de poder.

Sabendo disso, cada vez mais, as marcas buscam informar as suas ações para um grande número de pessoas, que com o uso das redes sociais, a conversa tem se tornado muito mais personalizada e individual, interferindo na cultura das instituições comerciais e consumidores e isso vem ampliando o alcance das interações. A respeito disso, Jenkins (2014) diz que:

Essa mudança - de distribuição para circulação - sinaliza um movimento na direção de um modelo mais participativo de cultura, em que o público não é mais visto como simplesmente um grupo de consumidores de mensagens pré-construídas, mas como pessoas que estão moldando, compartilhando, reconfigurando e remi- xando conteúdos de mídia de maneiras que não poderiam ter sido imaginadas antes. E estão fazendo isso não como indivíduos isolados, mas como integrantes de comunidades mais amplas e de redes que lhes permitem propagar conteúdos muito além de sua vizinhança geográfica (JENKINS, 2014, p.24).

A nossa atenção e o nosso imaginário estão voltados para nichos e cenários que são fontes produtoras de protocolos de confiança, ou seja, é uma construção de contato entre o "eu" e o "outro", que molda os atores sociais. Cada vez mais as pessoas podem assistir ou ler uma reportagem ou ouvir um programa de rádio e, através da Internet, procuram informações mais específicas a respeito do tema de seu interesse, proporcionando uma busca ainda mais focada sobre o que se desejam consumir. É nesse ponto que se fazem presentes as instituições e a midiatização das marcas. Negroponte (1995) complementa:

Os computadores estão se tornando cada vez menores. É de se esperar que você venha a carregar no pulso amanhã aquilo que hoje você tem em cima da mesa e que, ainda ontem, ocupava uma sala inteira (NEGROPONTE, 1995, p.141).

Conectadas pela Web, as pessoas se deparam com comerciais vinculados aos vídeos e textos que estão buscando assistir e ler, de forma muito mais ágil. O comportamento dos indivíduos neste espaço é monitorado pelos mecanismos de busca, que transforma em dados e, se analisados, podem ser utilizados como base para estratégias de marketing de marcas. "No mundo digital, o meio não é a mensagem: é uma das formas que ela assume (NEGROPONTE, 1995, p.73)". Sejam por fotos, vídeos, textos, emojis e hashtags, tudo comunica e se torna dado.

\section{Sociedade e ubiquidade midiática}

O fato de muitas pessoas terem consigo computadores de bolso ou vestíveis, faz com que elas possam compartilhar informações de qualquer lu- 
gar, em diversas plataformas e através de vários dispositivos, corresponde ao fato de estarem expandindo a rede de informação e de comunicação digital para além dos computadores portáteis. Esse fenômeno se constrói a partir de objetos transportáveis e dos ambientes, estabelecendo uma relação entre os espaços físicos, o cotidiano social e a rede virtual por meio do smartphone, do Global Positioning System (GPS), ou dos chips diversos e, invisivelmente, dos territórios servidos pela conexão sem fio - $\mathrm{Wi}^{-\mathrm{Fi}^{3}}$ ou bluetooth ${ }^{4}$.

A noção de uma informação ambiente, também denominada 'informática física', 'média tangível', ou 'ubimedia', segundo Adam Greenfiel (2006), anuncia um novo paradigma de interação entre a informação digital acessível em todos os lugares, dependendo do contexto e de onde se situam os indivíduos e os objetos comunicantes. Sobre a concepção da arquitetura da cidade e dos espaços comerciais, a informação ambiente define uma nova paisagem urbana, desenhada pelas novas estruturas espaciais informativas como painéis digitais, fachadas eletrônicas, estações de conexão e terminais de serviços digitais. Tudo isso para facilitar o dia a dia, para que os cidadãos possam se engajar e participar de uma comunicação coletiva e midiatizar conteúdos, gerando novas interações.

Exemplos do comportamento das pessoas frente à midiatização não faltam. Hoje, não basta mais realizar uma comemoração ou um encontro com amigos se não puder postar uma foto ou registrar num Stories ${ }^{5}$ (Instagram e/ou Facebook) para toda a rede informado que este encontro

3 Termo utilizado como sinônimo para a tecnologia IEEE 802.11, que permite a conexão entre diversos dispositivos sem fio. Disponível em https://www.tecmundo.com.br/wi-fi/197-o-que-e-wifi-.htm. Acesso em 03 de jul. 2017.

4 Tecnologia de comunicação sem fio que permite a troca de dados e arquivos entre celulares, computadores, scanners, fones de ouvido e demais dispositivos de forma rápida e segura. Disponível em http://www.techtudo.com.br/artigos/noticia/2012/01/bluetootho-que-e-e-como-funciona.html. Acesso em 03 de jul. 2017.

5 Sua principal característica é dar aos usuários a possibilidade de criarem vídeos curtos e poderem adicionar desenhos e emojis para decorar seus vídeos, que desaparecem depois de 24 horas da sua publicação. Disponível em https://postcron.com/pt/blog/ instagram-stories/. Acesso em 18 de abr. 2018 aconteceu e que foi regado a um café, almoço ou jantar, em determinado lugar, ou que brindou-se com o vinho $X$ ou com o espumante Z. Seguindo tal perspectiva, muitas vezes, as pessoas compram determinados produtos, consomem alguma informação e compartilham nos seus perfis individuais nas redes sociais, querendo apenas informar que possuem determinado produto ou uma ideia de como utilizá-lo e contribuir com outras pessoas a partir de uma percepção pessoal sobre uma experiência própria de consumo.

Sobre isso, José Luiz Braga no texto Circuitos versus campos sociais ensina que: "(...) entre produtor e receptor, importa o fato de que este último faz seguir adiante as reações ao que recebe" (BRAGA, 2012, p. 39). E faz-se constantemente, dando opinião e contribuição para o evento ou a mensagem propagada.

Os exemplos acima evidenciam o fato de que as pessoas, num geral, midiatizam e é preciso criar sentido, senão, os amigos e seguidores não "curtem" ou não compartilham as informações postadas, ou seja, são ignoradas. Ainda no texto Circuitos versus campos sociais, José Luiz Braga cita Fausto Neto que reforça a ideia do reconhecimento: "A circulação é, então, "transformada em lugar no qual produtores e receptores se encontram em jogos complexos de oferta e reconhecimento" (FAUSTO NETO apud BRAGA, 2012, p. 39). A comunicação atual é ubíqua - está presente em todos os lugares ao mesmo tempo, independente da conversa ser presencial ou virtual.

\section{As selfies e os estudos de mercado}

Um dos comportamentos mais corriqueiros da sociedade contemporânea é a participação nas redes sociais e o compartilhamento de selfies6. As pessoas têm levado a Internet consigo o tempo todo, estando on-line em casa e fora dela. Isso permite que elas estejam conectadas e par-

6 Ato de tirar fotos de si mesmo, ou seja, corresponde ao termo autorretrato e é uma foto compartilhada na internet. Disponível em https://www.significados.com.br/selfie/. Acesso em 03 de jul. 2017. 
ticipando ativamente na Web, seja como consumidor de conteúdos diversos, a trabalho ou estudo. Uma vez que carregam consigo smartphones e tablets, a selfie se torna uma expressão exclusiva do mobile.

Há quem pense que o autorretrato é uma atitude narcisista, uma vontade do indivíduo se exibir para uma câmera e postar algo em suas redes sociais como sendo incrível ou como se só ele tivesse acesso exclusivo ou, de alguma forma, fosse uma pessoa privilegiada por ver ou sentir algo especial num determinado momento. Porém, essa prática pode ter outra conotação, que é o compartilhamento de uma situação com os amigos e que ela serve de registro do cotidiano, de visualização da existência e da construção de identidade. Recuero (2014) contribui dizendo que: "[...] as conversações estudadas pelos atores seriam, também, formas de construir performances que constroem audiência impressões a respeito de quem são os integrantes" (p.59).

Atualmente, as selfies, além de configuração da estética e da linguagem do cotidiano são um sintoma da cultura, pois revelam a relação das pessoas com as imagens, o imaginário e, principalmente, com a sua construção identitária no espaço social, agora, mediado pelas tecnologias. Com a selfie, as pessoas estão tendo a oportunidade de expor seu rosto/corpo, ação que até pouco tempo era exclusiva de celebridades ou de pessoas que tinham recursos financeiros para este fim.

A selfie também significa o individuo afirmar que se encaixa numa determinada ideia, numa tribo, num conceito e se engaja com aquelas pessoas, ambiente ou conceito e elas sociabilizam de forma móvel. Por comunicarem comportamentos e preferências, a rede social Instagram é um ex-

\footnotetext{
7 Rede social de fotos para usuários de Android e iPhone. Trata-se de um aplicativo gratuito que pode ser baixado e, a partir dele, é possível tirar fotos com o celular, aplicar efeitos nas imagens e compartilhar com seus amigos. Há ainda a possibilidade de postar essas imagens em outras redes sociais, como o Facebook e o Twitter. No Instagram, os usuários podem curtir e comentar nas suas fotos e há ainda o uso de hashtags (\#) para que seja possível encontrar imagens relacionadas a um mesmo tema, mesmo que as pessoas que tiraram essas fotos não sejam suas amigas. Disponível em https://canaltech.com.br/o-que-e/instagram/o-quee-instagram/. Acesso em 03 de jul. 2017.
}

celente espaço para o estudo dessas informações sociais, que podem ser utilizadas de forma positiva para a melhoria de cidades, empresas e espaços comuns, bem como para a mobilização de pessoas e engajamento com causas e marcas.

\section{K Stogram}

Sabendo a importância que as redes sociais têm na vida das pessoas e entendendo que uma boa parte das imagens compartilhadas nesses espaços são selfies, as marcas podem buscar compreender melhor o mercado utilizando como recurso softwares gratuitos, como o 4K Stogram. Esse programa - que pode ser facilmente encontrado nas buscas do Google para download gratuito, em 13 idiomas, incluindo o português e pode ser utilizado em plataforma Windows, macOS ou Linux -, permite baixar imagens do Instagram e, através dele, pode-se pesquisar pessoas em específico, hashtags ${ }^{8}$ ou localizações. É possível que qualquer pessoa faça a pesquisa na busca e ele vai carregar as imagens que têm indicação daquela localização ou hashtag pesquisada. Depois que feita essa pesquisa, tem-se acesso às imagens e às legendas, bem como ao perfil das pessoas que fizeram essas postagens. Importante que essa captura de dados restringe-se para perfis públicos?.

Esse tipo de aplicativo é considerado uma ótima ferramenta de apoio para estratégias de marketing, pois auxilia o entendimento e o mapeamento do mercado. Não precisa ser exclusivamente este, a ideia é desmistificar a máxima de que é preciso um alto investimento financeiro pa-

\footnotetext{
8 Palavra-chave antecedida pela cerquilha (\#) que as pessoas geralmente utilizam para identificar o tema do conteúdo que estão compartilhando nas Redes Sociais. A adesão delas se tornou popular no Twitter e se disseminou para as maiores mídias sociais da atualidade. Disponível em https://marketingdeconteudo.com/oque-e-hashtag/. Acesso em 18 de abr. 2018.

9 É possível fazer download de fotos de perfis privados no Instagram, mas para isso, as pessoas devem permitir que quem fizer essa busca o siga. No momento que utiliza-se o $4 \mathrm{~K}$ Stogram, os perfis pesquisados não são notificados de que o seu conteúdo está sendo utilizado nessa busca. Disponível em https:// www.4kdownload.com/pt-br/products/product-stogram. Acesso em 18 de abr. 2018
} 
ra ter acesso a esses dados ou uma grande equipe especializada nesse tipo de análise para fazer. $\bigcirc$ fato é que se dedicado um tempo e tendo curiosidade para ir atrás das informações, qualquer pessoa pode ter acesso a esses dados. A esse respeito, Cobra (1997) explica que:

A adoção do conceito de marketing deve levar em conta as oportunidades de mercado. Nenhuma empresa estará disposta a investir em marketing, se não visualizar um retorno compensador. Para maximizar as oportunidades de mercado, é preciso identificar o público-alvo principal e o público-alvo secundário de forma a satisfazer suas necessidades através de produtos ou serviços de valor (COBRA, 1997, p.33).

A partir dessa ferramenta é possível identificar melhor o público-alvo que se deseja impactar com uma campanha de marketing e observar o lugar e a cultura que essas pessoas estão inseridas. Com o apoio da tecnologia tem-se muito mais recurso para mapear o lugar e os seus sentidos; as linguagens e redes; e as múltiplas culturas nos mesmos espaços, especialmente se forem utilizados softwares que agilizam esse mapeamento. Anderson (2006), diz que:

As pessoas que fazem parte dessa multidão talvez não se considerem fornecedores de recomendações ou de orientações. Mas todos os dias surgem cada vez mais softwares que observam suas atitudes, delas extraindo conclusões (ANDERSON, 2006, p.106).

Para exemplificar, com o 4K Stogram, foi realizado um teste de localização sobre a cidade de Gramado, no Rio Grande do Sul. Suponhamos que se tem a ideia de abrir um café nessa cidade, a partir das informações coletadas pelo software podemos vir a ter uma ideia dos lugares que as pessoas mais utilizam para tirar as suas fotos, se têm preferências por selfies individuais ou em duplas, ou grupos. Essas imagens em duplas podem indicar uma presença grande de casais que buscam a cidade para passear ou grupos de familiares ou amigos, se assim identificados. As informações a partir desse recurso são importantes até para observarmos a estrutura do estabelecimento, se é importante investir em espaços para uma ou duas pessoas ou grupos e tornar os ambientes atrativos e aconchegantes para quem ali frequentar se sinta bem e tenha vontade de fotografar, registrando boas experiências.

Indo mais a fundo, é possível observar também quais são os pratos mais fotografados/recomendados pelo público que frequenta o espaço e o que as pessoas escrevem nas legendas. Essas manifestações espontâneas contribuem para a melhoria do cardápio oferecido, tanto pelo sabor, quanto pela apresentação; bem como o atendimento, a estrutura, as formas de pagamento, os preços e o ambiente como um todo.

Os novos formadores de preferências somos nós. Agora, a propaganda boca a boca é uma conversa pública, que se desenvolve nos comentários de blogs e nas resenhas de clientes, comparadas e avaliadas de maneira exaustiva. As formigas têm megafones (ANDERSON, 2006, p.97).

Entendendo que cada indivíduo pode emitir suas opiniões públicas, por meio da análise das imagens a partir de softwares como o 4K Stogram, pode-se perceber quais os ambientes que as pessoas frequentam: se são feitas mais fotos ao ar livre, próximo a estabelecimentos públicos ou comerciais, o que chama mais a atenção dessas pessoas nesses locais; ou ainda, sendo comércio, o que as pessoas estão fazendo, consumindo e/ou falando sobre o ambiente, como estão vestidas, qual o seu comportamento em diferentes épocas, levando em consideração que as estações do ano são bem específicas no Rio Grande do Sul.

Essas questões indicam as estruturas arquitetônicas, o estilo e a decoração de ambiente que estimulem as pessoas a fotografarem e contribuírem para a divulgação do espaço. Hoje, a localização dos estabelecimentos comerciais é muito importante na sua divulgação. As pessoas se locomovem o tempo todo com smartphones que conseguem entender os seus trajetos e oferecer indicações de lugares de acordo com a sua preferência, bem como as melhores rotas, informações de trânsito e condições climáticas. Por isso, ao di- 
vulgar um estabelecimento comercial nas redes sociais, além de imagens do lugar e das informações adicionais, é imprescindível conter a localização e o horário de atendimento, pois podem ser dados cruciais para a escolha de uma pessoa frequentar aquele espaço ou não.

Pensando sobre as redes sociais, é possível fazer uma análise da presença online: quem sou (Facebook), o que eu estou fazendo (Twitter) e onde estou (Foursquare). Já com o Instagram, por meio da postagem de imagens, o indivíduo pode se auto mostrar, ou indicar com quem está, o que está fazendo e a sua localização, fazendo com que a análise seja ainda mais específica. Claro que essa ferramenta não pode ser utilizada isoladamente, mas ela contribui para evidenciar algumas questões específicas que no dia a dia que podem passar despercebidas nos ambientes pesquisados.

Logicamente o 4K Stogram tem algumas limitações. A busca poderia ser ainda mais específica se fosse possível inserir as datas de início e fim da coleta de imagens, bem como ter a opção de um comparativo de uma macro e microrregião, como por exemplo, comparar um bairro em relação a cidade de Gramado. Sem contar, que os dados poderiam vir mais completos, como: as hashtags que mais aparecem nessa busca, as pessoas que mais participam (comentam e curtem) e os dias da semana com maior número de postagens. Todos esses dados refinariam ainda mais as contribuições para as equipes de marketing embasarem suas estratégias. Mesmo assim, é uma excelente ferramenta para captura de dados e de comportamento para os negócios.

\section{Considerações finais}

A tecnologia está nos fazendo presente em diversos ambientes e nos conectando cada vez mais a outras pessoas e instituições. Está mais fácil compartilhar o nosso dia a dia, as nossas atividades, com quem estamos, os interesses pessoais, os projetos profissionais e lugares que frequentamos com pessoas que têm ligação direta ou indireta aos indivíduos. As pessoas têm se relacionado de um jeito diferente, pois boa parte das suas conversas são mediadas pela Internet, através das redes sociais. Obviamente, não é possível estar sempre próximo de todas as pessoas que se gosta, pois cada um tem a sua rotina, seus compromissos e a sua disponibilidade para estar presente com um grupo de amigos, por exemplo, nem sempre é a mesma para cada membro de um grupo. Porém, as redes sociais dão a sensação das pessoas estarem longe, mas ao mesmo tempo perto, pois facilitam a comunicação e agilizam a gestão e a realização das tarefas.

O que num primeiro momento pode parecer um ato ingênuo, com os diversos usos da tecnologia para interação, é possível conectar as informações que são trocadas e publicadas nos perfis pessoais, bem como as pesquisas no Google e obter uma base de dados que auxilia no mapeamento do público para embasar e desenvolver ações de comunicação e de marketing. Ao configurar um smartphone, as empresas têm acesso aos dados dos usuários e elas constantemente vêm os alimentando com informações que se revertem em ofertas de produtos e serviços.

Nesse sentido, também acontece uma nova forma de oferta por parte do mercado. A população é constantemente estimulada a comprar, muitas vezes, sem que tenha uma real necessidade de adquirir determinados produtos, mas os mecanismos de busca e anúncios patrocinados on-line estão configurados para trazer ofertas até que pela sedução, sejam convencidas de que aquele produto é importante e venha a consumir. Ou estabelecimentos físicos, que com arquitetura e proposta de experiências diferenciadas e atraentes, têm chamado a atenção do público, sendo um convite a conhecer e experimentar.

Se de um lado essas estratégias podem facilitar a vida, poupando tempo, percebe-se também que as pessoas estão cada vez mais ansiosas, querendo trabalhar mais para ter mais dinheiro e consumir mais, como um ciclo vicioso sem fim, pois à medida que tem-se mais recursos financeiros, gasta-se mais e nunca se está satisfeito com o que tem.

Concluo o presente artigo dizendo que a tecnologia é uma realidade com a qual as pessoas estão cada vez mais ambientadas e não vivem mais sem ela, pois traz uma série de facilidades, nos conecta com mais pessoas e agiliza as atividades do 
dia a dia. No entanto, o cenário da ubiquidade é complexo e temos mais questões a serem observadas e trabalhadas a partir dessa realidade.

A digitalização das informações traz benefícios, como a liberdade de poder compartilhar as experiências diárias e dar a nossa opinião sobre os mais diversos assuntos com os quais nos identificamos, por meio de postagens, mas ao mesmo tempo devemos estar conscientes de que os nos- sos dados estão sendo observados por empresas que os utilizam para suas estratégias de comunicação e marketing. É o caso do uso do software 4K Stogram, que pode ser uma boa ferramenta para este fim, mas que desafia a pesquisar mais e desenvolver outras ferramentas ainda mais específicas para a coleta de dados e o estudo do comportamento cada vez mais complexo das pessoas na sociedade contemporânea. 


\section{Referências}

ANDERSON, Chris. A cauda longa: Do mercado de massa para o mercado de nicho. Rio de Janeiro: Elsevier, 2006.

"Bluetooth". Disponível em: <http://www.techtudo.com.br/artigos/noticia/2012/01/bluetooth-o-que-e-e-comofunciona.html>. Acesso em 03 de jul. 2017.

BRAGA, José Luiz. Circuitos versus campos sociais. In: MATTOS, MA., JANOTTI JUNIOR, J., JACKS, N. (orgs.) Mediação \& midiatização [online]. Salvador: EDUFBA, 2012. pp. 29-52.

COBRA, Marcos. Marketing Básico: Uma perspectiva brasileira. São Paulo: Atlas, 1997.

GREENFIELD, Adam (2006). Every[ware]: La révolution de l'ubimedia. France: FYP, 2007. In: LEITE, Julieta. A ubiqüidade da informação digital no espaço urbano. Revista LOGOS, Rio de Janeiro, v.23, n.2, p.104-116, juldez. 2016.

"Hashtag". Disponível em: <https://marketingdeconteudo.com/o-que-e-hashtag/>. Acesso em 18 de abr. 2018.

"Instagram". Disponível em: <https://canaltech.com.br/o-que-e/instagram/o-que-e-instagram/>. Acesso em 03 de jul. 2017.

JENKINS, Henry. Cultura da Conexão: Criando valor e significado por meio da mídia propagável. São Paulo: Aleph, 2014.

MATTELART, Armand e Michèle. História das Teorias da Comunicação. São Paulo: Loyola, 1999.

MARTINS, Francisco e SILVA, Juremir. (org.) Para navegar no século XXI: Tecnologias do Imaginário e cibercultura. Porto Alegre: Sulina, 2000.

NEGROPONTE, Nicholas. A vida digital. São Paulo: Companhia das Letras, 1995.

4K Stogram. Disponível em: <https://www.4kdownload.com/pt-br/products/product-stogram>. Acesso em 18 de abr. 2018.

4K Stogram. Disponível em: <http://www.techtudo.com.br/tudo-sobre/4k-stogram.html>. Acesso em 02 de jul. 2017.

RECUERO, Raquel. A conversação em rede: Comunicação mediada pelo computador e redes sociais na Internet. Porto Alegre: Sulina, 2014.

"Selfie". Disponível em: <https://www.significados.com.br/selfie/>. Acesso em 03 de jul. 2017.

UGARTE, David de. O poder das redes: Manual ilustrado para pessoas, organizações e empresas, camadas a praticar o ciberativismo. Porto Alegre: EDIPUCRS, 2008.

"Stories". Disponível em: <https://postcron.com/pt/blog/instagram-stories/>. Acesso em 18 de abr. 2018.

"Wi-Fi". Disponível em: <https://www.tecmundo.com.br/wi-fi/197-o-que-e-wi-fi-.htm>. Acesso em 03 de jul. 2017. 